\title{
INTERVIEWS
}

\section{COLLABORATIVE LEARNING IN HIGH SCHOOLS: AN INTERVIEW WITH JARROD BOLIN}

\author{
BY LAURENCE RAW
}

Education specialist Jarrod Bolin worked closely with a group of high school learners in Texas to create papers suitable for presentation at the South West Texas Popular Cultural Conference in Albuquerque. This remarkable achievement was achieved out of class, with funding raised by the learners. In this interview, Bolin describes the creation of a remarkable creative and collaborative spirit that drove the group onwards. In the Editor's opinion, the venture represents an ideal example of what education should be.

$\boldsymbol{L R}$ [Laurence Raw]: When you began work with the learners, did you have any specific expectations? Were you given any prior information about their capabilities/shortcomings? And did that information influence you in any way?

JB: [Jarrod Bolin] Fortunately for me, when I was in graduate school, I had mentors who showed me how to be a member of the academic community. Specifically, Gerald Duchovnay, Robin Reid, Karen Hartmann Roggenkamp, Hunter Hayes, and Susan Stewart (all of Texas A\&M University-Commerce) made sure that each of their classes included assignments that could be rewritten for journals, reviews, or as conference papers. Duchovnay consistently required us to do conference-style presentations in his classes because he wanted us to know how to exchange views with others, not just regurgitate what was on the syllabus. No professor ever encouraged my work to extend beyond the classroom. I knew that academic conferences existed - my father is an English professor, so he attended them over a decade or so - but I thought they were strictly for professors. My graduate school professors challenged me to submit a proposal in my very first semester.

So, to answer your questions, when I started my own program, I certainly had specific expectations, and they were idealistic and challenging, just like the expectations my mentors had for me. I knew my own high school learners were unprepared. I knew that they had no idea what they would be getting into, or how much work it involved, or what it was supposed to look like. And I knew that didn't matter. If I worked with them the way my mentors had worked with me, then they might have a good chance of being successful. 
That first year, I knew most of the participants beforehand. I had been an educator at the Singley Academy for a year, and three of the five had been in my class the previous year. In fact, two of my learners, at the end of their sophomore year, asked me to start a film club because they knew I had studied film in college. I talked to them about academic conferences, half-expecting them to think I was crazy; but both of them were enthusiastic and welcomed the challenge. Because I had worked with them previously, I knew these two were incredibly intelligent and could put together a presentation worthy of a conference. So, I set about finding a conference that would fit our academic schedule, and SWPACA (Southwest Texas Popular Culture Association Conference, held each February in Albuquerque) is perfect for that. In addition, this conference is a place for learners to do that - to learn! - about how to belong to the academic community, so it seemed like the perfect fit.

LR: What strategies did you adopt to create a learning community? How did you create an atmosphere of mutual self-belief or shared purpose? Did that involve setting aside your prior expectations of your learners and treating them on their own terms?

$\boldsymbol{J B}$ : That first year, my community came pre-built. The two young students who asked me to start the club invited a couple of their friends, so I cannot take credit for their cohesion. With only five of them, it was very easy to get everyone on the same schedule, have regular meetings, and enjoy each other's company while working hard on research. The following year, we grew. But by then, I had five veterans of the SWPACA conference, so I used those writers as mentors. They had responsibility over some of the new members and taught them how to navigate the online databases, what an abstract should look like, how to make an academic argument, and how to put together the presentation once the proposal was accepted. I have to say, that year was something very special. I watched sixteen-year-olds teach other sixteen-year-olds how to be members of an academic community. It blew my mind.

As to the atmosphere of mutual self-belief: I had already seen the example set by Gerald Duchovnay and Eric Gruver when they brought undergraduates to conferences. Witnessing those undergraduates present their projects was foundational in my own firm faith that my own learners could do it, too. I knew that these teens were just as capable as those undergrads, but they were rarely challenged to do anything beyond expectations for standardized testing. The public high school system in Texas is very, very focused on standardized testing, so there aren't many enrichment opportunities.

When working with these teens, though, I did have some expectations that demanded revaluation, For example, I tried to get the learners to create 
annotated bibliographies, but too quickly (we'd only just been accepted, so I didn't give the learners enough time to digest all of these new tasks). So my timeline had to be rapidly adjusted. Yet my learners did not disappoint me; they presented with aplomb and enthusiasm that matched even the most devoted graduate student.

LR: Did you encounter obstacles in that process of preparing learners for conferences? What were they?

JB: As mentioned previously, I definitely had to shift my timeline to accommodate my learners who were brand new to the process - and they take eight classes each! They spend close to 40 hours per week in class. Imagine trying to put together a college-level presentation while also juggling eight classes (none of which have anything to do with the conference); homework for all of those classes; and housework for your parents or guardians.

Besides that, I had to convince my administrators that this was a worthwhile endeavor. The instinct of any public school system is to act conservatively, cautiously. They have to protect themselves from litigation so often that it's hard to do innovative things that require travel with learners. Not only that, but most high-school educators only go to conferences to learn about pedagogy. There aren't a lot of conferences where original, content-driven research is at the forefront, and there certainly aren't a lot that would invite learners to present. It's a completely different culture for high school educators as compared to higher education, so I had to do a lot of convincing that this wasn't a film festival where the learners would skip three days of class to watch movies all day.

Once we got approved, we had to raise funds. Irving is a Title 1 district, meaning we are at the highest level of poverty. So, I wanted to create a club that offered opportunities for enrichment, and I wanted the only barrier to be academic. For that to happen, the trip had to be free to the students. We had no budget whatsoever, though, and no one was offering any handouts. So, I also taught these learners how to write grants and present to grant-awarding committees. My learners have, in the past three years, won over $\$ 16,000$ in grants for this project.

LR: To what extent did your institution support your endeavors? If as you say the Texas education system is so restrictive, did anyone accuse you of departing from the "real" business of education?

JB: It wasn't quite as dramatic as all that, but I did have to prove that the group's activities had merit that first year. My principal at the time had to sign off with the approval, and he was reluctant. So, I knew I had to show some 
progress. That year, my learners submitted their abstracts very early so that we could get approved earlier, too. I took a printout of one of the proposals and an acceptance letter to the principal, and he was shocked. "A learner wrote this?" he asked. "You didn't write it?" I told him that this is the caliber of work to expect from the club. After that, he signed off immediately. Support from the higher echelons came through pretty quickly once they saw the work the learners had produced.

Accusations of departing from the "real" business of education wasn't an issue, mostly because all of the work we do is outside of class.

\section{$L R$ : What was the reaction of the learners' parents? Did they support the venture or were there objections?}

JB: The first year, that was an issue. Several of the kids didn't even tell their parents for months after getting accepted for fear of refusal. Just like with the administration, though, once everyone saw the work the kids were doing, they were all very supportive. This is an issue every year, however, so every year, I have to make sure the parents understand how advanced the work is, and what a privilege it is for high school students to be accepted to a conference.

LR: How did you determine the syllabus of your work? Were you constrained in any way? If you were, how did you negotiate such constraints; if you weren't, what criteria governed what you wanted/chose to do? What were your objectives?

JB: I used the same tactics in creating my syllabus for this club as I did for my rhetoric classes: I tried to design a class that would be Advanced Topics in English for non-English Majors. Therefore, the material had to be quality work that was also highly relevant. I like to teach this way because, unlike me, most of my learners are not intrinsically motivated to read a lot of works. At the beginning of my career, I really struggled with this. "They're missing out on so many fantastic experiences by not wanting to read," I used to lament. But then I tried to figure out what made reading so appealing to me, especially reading classics. I was young and in love with pop culture when I was in high school, but I also loved the classics. After a lot of introspection, I recognized that it was because I had been reading for so long that I had a huge catalog of popular works under my belt by the time my instructors worked with me. Therefore, I started to recognize the allusions that had been present in some of my favorite works, but in sort of a backwards manner. Instead of reading a newer work and recognizing the allusion to a classic, I was reading a classic and realizing that, newer work must have been intertexting this! Since I was already emotionally 
invested in the popular culture, it made me love the classic that had inspired that popular work even more than I would have.

An example: when I was a kid, I had seen the Disney film The Lion King. I loved it, like most kids I knew who saw it. Once I was in high school, though, and my instructor told us that The Lion King was a retelling of Hamlet, that made me want to read Hamlet so much more than I had wanted to before knowing that information. So, I use lots of pop culture in my class, especially pop culture that includes references to classics, or works that obviously engage with theories that I want the students to study.

That first year, I used a Joe Cornish film, Attack the Block, to accomplish this task. By illustrating to these students the trope of the "white savior," then showing them how the film Attack the Block seems to intentionally undermine that stereotype, it made them all want to read more about that. In that way, when I gave them a chapter from Ella Shohat and Robert Stam's Unthinking Eurocentrism, it made the reading more palatable than it would have been if I'd have just told them, "Hey, read this." And I wanted that year to be about representation in media, so the Shohat and Stam chapter worked perfectly for that.

In my pedagogy, I see film as raw materials, and teach that to the students. There are "hard" films that they have had to watch, too, while in the club, although some "hard" films are also high-interest (like Pulp Fiction or Snowpiercer). So, we do lots of reading, but as a club, we do more reading outside of meeting times, and during meetings, a selected learner will present an academic argument about a specific film, then we'll watch the film. The only way for learners to participate in effective ways is if we have some common texts - both written and cinematic - which is why we stick with Shohat and Stam as a "tentpole text" that is required for them all. It includes vastly more theory than the typical high school assignment, so I never get criticism for being theory-light. In fact, many of the administrators who preview their work have a tough time reading some of their sources, which usually impresses those admins.

I must admit to being pedagogy-light though. My methods came from self-reflection. I know that it is because I was already interested in popular culture that my interest in canonical texts grew. My method is designed to recreate that as much as possible: show my learners popular culture that has merit, then introduce canon or theory. If any pedagogue were to see the beginning of my process, they would most likely have reservations, especially if they were traditionalist. However, the results have proved that the method works: these are advanced learners who are capable of holding their own at a conference despite the fact that they are still in high school, mostly sheltered from actual, rigorous methods of research and/or presentation. 


\section{Works Cited}

Attack the Block. Dir, Joe Cornish. Perf. John Boyega, Jodie Whittaker, Alex Esmail. Three Mils Studios, 2011. Film.

The Lion King. Dir, Roger Allers, Rob Minkoff. Perf. Matthew Broderick, Jeremy Irons, James Earl Jones. Walt Disney, 1994. Film.

Pulp Fiction. Dir. Quentin Tarantino. Perf. John Travolta, Uma Thurman, Samuel L. Jackson, Miramax, 1994. Film.

Snowpiercer. Dir. Bong Joon Ho. Perf. Chris Evans, Jamie Bell, Tilda Swinton. Snowpiercer, 2013. Film.

Stam, Robert, and Elia Shohat. Unthinking Eurocentrism: Multiculturalism and the Media. 1994. New York, 2013. Print. 